\title{
Ectopic expression of HSDL2 is related to cell proliferation and prognosis in breast cancer
}

This article was published in the following Dove Press journal:

Cancer Management and Research

\author{
Bing Dong' \\ Yang Yang ${ }^{1,2}$ \\ Anna Han' \\ Songnan Zhang ${ }^{3}$ \\ Zhenhua Lin ${ }^{1,2}$ \\ Yixuan Wang' \\ Junjie Piao ${ }^{1,2}$
}

'Department of Pathology \& Cancer Research Center, Yanbian University Medical College, Yanji I33002, People's Republic of China; ${ }^{2}$ Key Laboratory of the Science and Technology Department of Jilin Province, Yanji I33002, People's Republic of China; ${ }^{3}$ Department of Oncology, Affiliated Hospital of Yanbian University, Yanji I3302, People's Republic of China
Correspondence: Junjie Piao Department of Pathology \& Cancer Research Center, Yanbian University Medical College, No. 977, GongyuanRoad, Yanji City 133002, People's Republic of China

Email piaojunjie@ybu.edu.cn
Purpose: Human hydroxysteroid dehydrogenase-like 2 (HSDL2) is a characterized SDR gene that not only catalyses the oxidation and reduction of multiple substrates but also regulates different metabolic and signalling pathways. Accumulating evidences suggest that HSDL2 play an important role in cancer progression. However, the role of HSDL2 in breast cancer has not yet been determined. Thus, this study aims to explore the relevance of HSDL2 in breast cancer progression.

Patients and methods: The location of HSDL2 protein was detected in MDA-MB-231 breast cancer cells by using immunofluorescence (IF) staining. The expression level of HSDL2 was evaluated by immunohistochemical (IHC) staining in 119 breast cancer tissues and 40 normal breast tissues. Then, the correlations between the overexpression of HSDL2 and clinicopathological features of breast cancer patients were evaluated by using the chisquare test, and the survival rates were calculated by the Kaplan-Meier method. In addition, the role of HSDL2 in breast cancer proliferation was assessed by MTT and colony formation assays, and cell cycle distribution was detected by flow cytometry analysis and Western blot. Results: IF staining and IHC analysis consistently showed that HSDL2 was predominantly expressed in the cytoplasm of breast cancer cells. The positive rate of HSDL2 protein was significantly higher in breast cancer tissues $(87.4 \%, 104 / 119)$ than in adjacent normal breast tissues $(25 \%, 10 / 40)(p<0.01)$. A high expression of HSDL2 protein was significantly associated with high histological grades, late clinical stages and low survival rates. Moreover, multivariate analysis indicated that HSDL2 protein was an independent prognostic factor in breast cancer patients. Studies in vitro showed that HSDL2 depletion reduced cell proliferation and induced cell cycle arrest in breast cancer.

Conclusion: In conclusion, this study indicated that HSDL2 plays a role in promoting the development of breast cancer. HSDL2 could be a valuable prognostic biomarker and a potential therapeutic target for patients with breast cancer.

Keywords: HSDL2, breast cancer, growth, survival, prognosis, biomarker

\section{Introduction}

Breast cancer is one of the most common malignancies for women and is the leading cause of cancer death among females worldwide. ${ }^{1}$ Globally, up to 1.4 million new patients are diagnosed with breast cancer each year, which is the cause of death for one-third of these patients. ${ }^{2}$ Recently, molecular diagnosis and targeted therapy have led to great advances and progress in cancer treatment and have provided opportunities for patients to receive personalized treatment. For instance, the use of a humanized monoclonal antibody against HER2, such as trastuzumab and lapatinib, has been shown to improve the survival of breast cancer patients. ${ }^{3}$ Despite the significant progress in the treatment of breast cancer, the 
clinical prognosis of breast cancer patients is still poor. Therefore, breast cancer treatment requires more effective biomarkers and therapeutic targets.

The members of the short-chain dehydrogenase/reductase (SDR) superfamily catalyse the oxidation and reduction of multiple substrates, such as steroids, fatty acids, and xenobiotics. ${ }^{4}$ Some studies have shown that SDRs can regulate different metabolic and signalling pathways, and SDR enzyme dysfunctions can lead to diseases such as Alzheimer's disease, malignant tumours and obesityrelated diseases. $^{5-7}$ Human hydroxysteroid dehydrogenase-like 2 (HSDL2) is located at the chromosome 9q32 loci and encodes the HSDL2 protein, which is characterized as an SDR. ${ }^{8}$ HSDL2, a member of the SDR family, was reported to be correlated with glioma and ovarian cancer. $^{9,10}$ However, to date, the relations between HSDL2 and breast cancer have not yet been reported.

Thus, to gain insight into the role of HSDL2 in the initiation and progression of breast cancer, we detected the expression level of HSDL2 in normal breast tissues and breast cancer tissues and investigated the correlation between HSDL2 expression and clinicopathological features. We also evaluated the prognostic value of HSDL2 in breast cancer patients and explored the role of HSDL2 in breast cancer cell growth in vitro.

\section{Materials and methods}

\section{Cell culture}

The human breast cancer cell lines MDA-MB-231 and MDA-MB-468 were purchased from the Cell Bank of the Chinese Academy of Medical Science (Shanghai, China) and conserved by the Cancer Research Center of Yanbian University. Cells were cultured in Dulbecco's Modifified Eagle Medium (DMEM) (Gibco, Gaithersburg, MD, USA) supplemented with penicillin (100 U/ml), streptomycin $(100 \mu \mathrm{g})$ and $10 \%$ fetal bovine serum (FBS). All cells were maintained in $5 \% \mathrm{CO}_{2}$ at $37{ }^{\circ} \mathrm{C}$.

\section{Transfection}

HSDL2 siRNA (si-HSDL2) targeting the human HSDL2 gene and siRNA duplexes with non-specific sequences were used as negative controls (si-Control). All sequences (Table 1) were designed and synthesized by RiboBio (Guangzhou, China). pCMV6-HSDL2 overexpression plasmid was purchased from Origene (Rockville, USA). Transfections were performed by using Lipofectamine 3000 (Invitrogen, CA, USA) according to the manufacturer's protocol.
Table I The sense sequences of si-RNA

\begin{tabular}{|l|l|}
\hline Si-HSDL2\#I & 5'-GGCAAAGCTATTGCATTGA-3' \\
Si-HSDL2\#2 & 5'-CTTCTAGGCACAATCTATA-3' \\
Si-HSDL2\#3 & 5'-GCAGCAAAGGATGGAGCAA-3' \\
\hline
\end{tabular}

\section{Oncomine database}

We utilized the Oncomine database (https://www. oncomine.org/resource/main.html) to evaluate the expression level of HSDL2 in breast cancer. We retrieved a breast cancer-related mRNA microarray dataset to assess correlations between HSDL2 and breast cancer. ${ }^{11}$ Then, we predicted the correlation between the mRNA expression of HSDL2 and the survival time of breast cancer patients by using KM plotter and the Protein Atlas database.

\section{Ethics statement}

This study was conducted in accordance with the Declaration of Helsinki and approved by the Human Ethics and Research Ethics committees of Yanbian University Medical College in China.

\section{Immunofluorescence (IF)}

The sub-cellular localization of HSDL2 protein in MDAMB-231 cells was detected by using IF staining. Cells were grown on coverslips to $70-80 \%$ confluence and fixed in $4 \%$ paraformaldehyde for $10 \mathrm{~min}$. Then, the cells were permeabilized with $0.5 \%$ Triton X-100 for 10 min. Blocking was performed using 3\% Albumin Bovine V (A8020, Solarbio, Beijing, China) in PBS supplemented with $0.3 \%$ Triton X-100 for $1 \mathrm{~h}$ at RT. AntiHSDL2 Antibodies (15631-1-AP, Proteintech) were diluted in $1 \% \mathrm{BSA} / \mathrm{PBS} / 0.3 \%$ Triton $\mathrm{X}-100$ and incubated with the cells at $4{ }^{\circ} \mathrm{C}$ overnight. After washing with PBS, the cells were incubated with fluorochrome-labelled secondary antibodies (Alexa Fluor ${ }^{\circledR} 568$ goat anti-rabbit IgG $(\mathrm{H}+\mathrm{L}))(\mathrm{A} 11004,1: 1,000$, Invitrogen, USA) for $1 \mathrm{~h}$ at RT. Next, the cells were counterstained with DAPI (C1006, Beyotime, Shanghai, China). Finally, the fluorescence signals were detected with a Leica SP5II confocal microscope (Heidelberg, Germany).

\section{Immunohistochemistry (IHC)}

IHC analysis was performed using the Dako LSAB Kit (Dako A/S, Glostrup, Denmark). Tissue sections were dewaxed with xylene and ethanol, followed by PBS washes and rehydration. Then, the endogenous peroxidase activity of the sections was quenched with $0.3 \% \quad \mathrm{H}_{2} \mathrm{O}_{2}$. 
Subsequently, the antigen was retrieved, followed by incubation with $1 \%$ BSA. The slides were then incubated with a primary antibody at $4{ }^{\circ} \mathrm{C}$ overnight. After incubation with a secondary antibody at RT for $30 \mathrm{~min}$, the slides were then incubated with a streptavidin-peroxidase complex. The peroxidase reaction was developed with 3,3'-diaminobenzidine, counterstained with Mayer's haematoxylin, dehydrated and mounted. Rabbit IgG isotopes were used as a negative control, and positive tissue sections were processed by omitting the primary antibody as a further negative control.

\section{Evaluation of IHC}

Two pathologists independently evaluated all tissue specimens. In cases of discrepancies, the final score was established with a reassessment by both pathologists on a double-headed microscope. We first observed staining in the whole breast lesion. Only the cytoplasmic expression patterns were considered positive staining. The staining was scored as "-" (negative, no or less than 5\% positive cells), "+" (5-25\% positive cells), “++" (26-50\% positive cells) or " +++ " (more than $50 \%$ positive cells). The "strongly positive" descriptor (HSDL2 overexpression) was assigned to samples scored as "++" and "+++". For survival analysis, the expression level was denoted as high HSDL2 expression ("++" and “+++") and low HSDL2 expression ("-" and "+").

\section{Cell viability assay}

The cells were plated $(5,000$ cells/well $)$ in 96 -well plates and incubated overnight at $37{ }^{\circ} \mathrm{C}$ in a humidified atmosphere containing $5 \% \mathrm{CO}_{2}$. After $24,48,72$ and $96 \mathrm{~h}$ of incubation, $20 \mu \mathrm{L}$ of MTT $(5 \mathrm{mg} / \mathrm{mL})$ was added into each well and incubated for $4 \mathrm{~h}$ under the same conditions. The supernatants were carefully removed. Then, $200 \mu \mathrm{L}$ of DMSO was added to each well, and the wells were thoroughly mixed for $10 \mathrm{~min}$. The absorbance value (OD) at $490 \mathrm{~nm}$ of each well was measured using a microplate reader (LabSystems Multiskan Ascent).

\section{Colony formation assay}

Single-cell suspensions were plated in six-well plates (200 cells/well) and incubated for 14 days at $37{ }^{\circ} \mathrm{C}$ in an atmosphere containing $5 \% \mathrm{CO}_{2}$. Then, the cells were fixed in $4 \%$ paraformaldehyde for $15 \mathrm{~min}$. After washing with PBS, they were stained with Giemsa for 25 mins. Finally, images of the colonies were taken, and the numbers were calculated. Statistical significance was calculated from each of three independent experiments.

\section{Western blot analysis}

Total protein was extracted for Western blot. The proteins were lysed in IP lysis buffer with protease inhibitors and then incubated on ice for $30 \mathrm{~min}$. Supernatants were collected by centrifugation $\left(15,000 \mathrm{rpm}\right.$ for $30 \mathrm{~min}$ at $\left.4{ }^{\circ} \mathrm{C}\right)$. Next, the protein samples were separated on SDS polyacrylamide gels and then transferred to PVDF membranes. The membranes were blocked for $2 \mathrm{~h}$ with $5 \%$ fat-free milk and incubated with primary antibodies at $4{ }^{\circ} \mathrm{C}$ overnight. Afterwards, primary antibodies were removed, and the membranes were washed again three times with TBST. Finally, the membranes were incubated with HRPconjugated secondary antibody for $2 \mathrm{~h}$ at RT. Detection by enzyme-linked chemiluminescence (ECL) was performed according to the manufacturer's protocol. The results were analysed quantitatively using the Chemiluminescent and Fluorescent Imaging System.

\section{Flow cytometry analysis}

Cells were harvested by trypsinization and washed twice with a PBS solution. Next, $500 \mu \mathrm{L}$ of cold PI staining solution was added to each tube and incubated for $15 \mathrm{~min}$ in the dark on ice. Cells were collected and analysed using a flow cytometer (BD Accuri C6, MI, USA) according to the manufacturer's instructions. The results were finally compared with those of the untreated control cells.

\section{Statistical analysis}

The data analysis was performed using SPSS 17.0 software and GraphPad Prism 6.0 software. The effect of HSDL2 on the clinical stage of breast tumours and histological grade was investigated by the Pearson chi-square test. Survival rate was analysed by the Kaplan-Meier method, and differences in the survival curves were analysed by log-rank tests. Cox proportional hazards regression was employed to assess the prognostic significance of factors in univariate and multivariate models. All observations were confirmed by at least 3 independent experiments. The results are presented as the mean $\pm \mathrm{SD}$. A value of $p<0.05$ was considered statistically significant.

\section{Results HSDL2 protein is overexpressed in breast cancer}

To investigate the role of HSDL2 in breast cancer, we evaluated the mRNA expression level of HSDL2 in breast 
cancer samples from microarray data obtained from the Oncomine database. The results showed that the expression level of HSDL2 mRNA was upregulated in breast cancer tissues compared with normal breast tissues (Figure $1 \mathrm{~A}$ and $\mathrm{B}$ ). We then predicted the correlation between the mRNA expression of HSDL2 and survival time of breast cancer patients by using KM plotter and the Protein Atlas database. A high expression of HSDL2 mRNA was correlated with short survival time in breast cancer patients (Figure 1C and D).

To verify the location of HSDL2 in breast cancer cells, we performed IF staining on MDA-MB-231 breast cancer cells. The results showed that HSDL2 protein was mainly located in the cytoplasm (Figure 2). In addition, we performed IHC staining on 119 breast cancer tissue samples and 40 normal breast tissue samples. Consistently, IHC staining of HSDL2 in breast cancer tissues also showed that HSDL2 was mainly located in the cytoplasm (Figure 3A-D). The positive rate of HSDL2 protein was significantly higher in breast cancer tissues $(87.4 \%, 104 / 119)$ than in adjacent normal breast tissues $(25 \%, 10 / 40)(p<0.01)$. Similarly, the strongly positive rate of HSDL2 protein was also significantly higher in breast cancer tissues $(48.7 \%, 58 / 119)$ than in normal breast tissues $(12.5 \%, 5 / 40)(p<0.01)$ (Table 2).
A

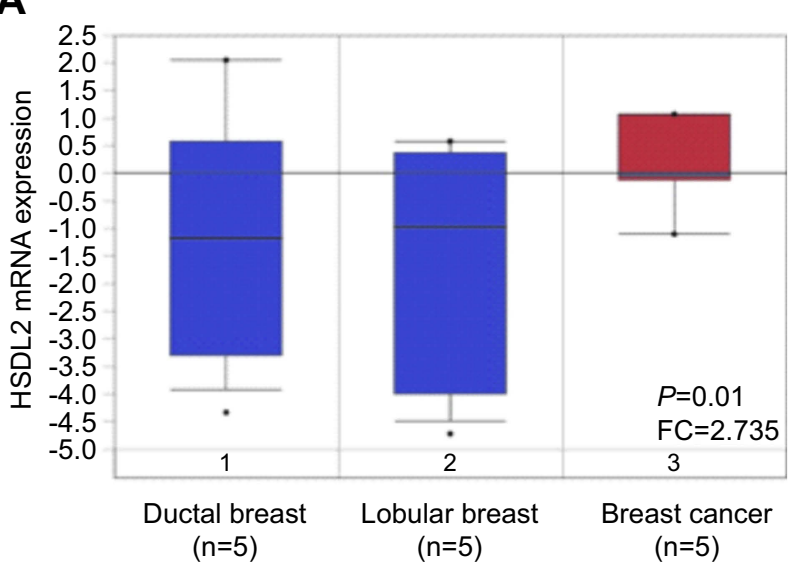

C

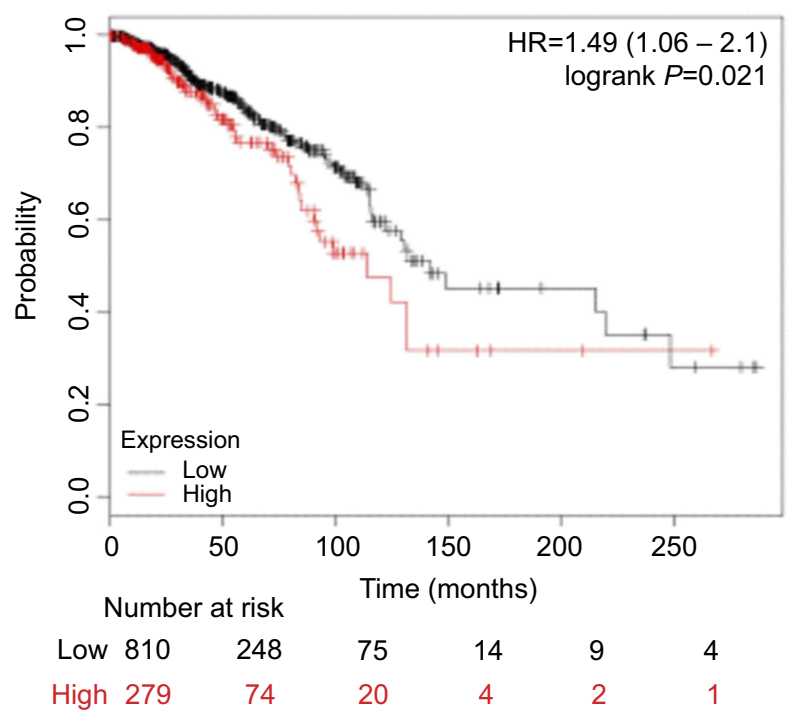

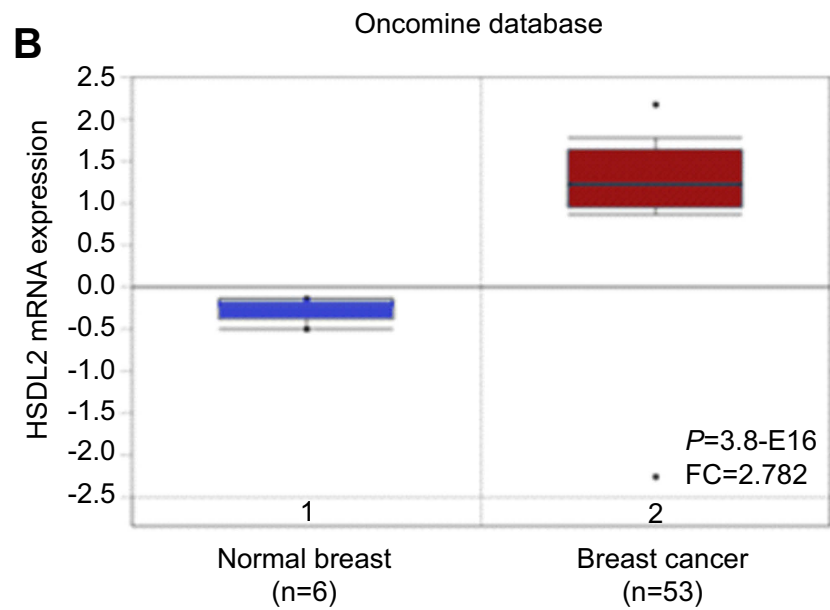

D

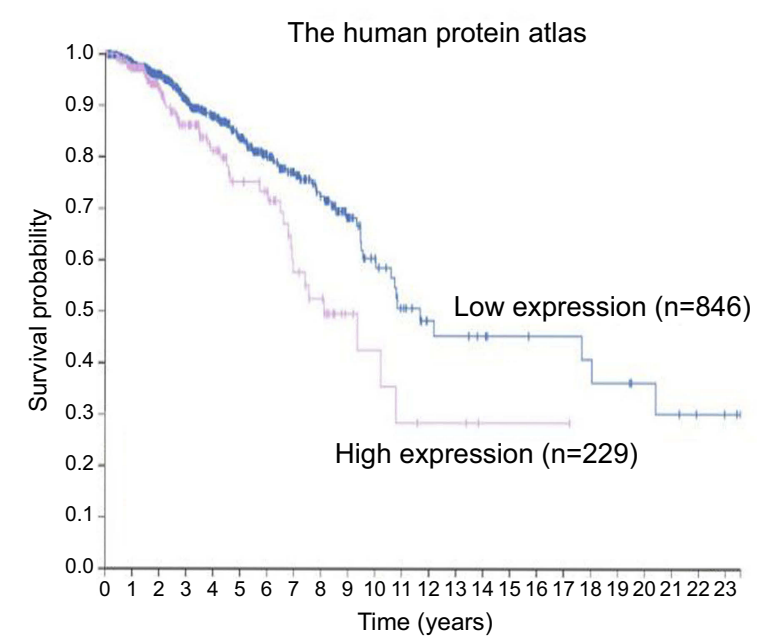

Figure I Expression of HSDL2 mRNA in breast cancer tissues.

Notes: (A-B) The expression levels of HSDL2 mRNA in normal and breast cancer samples were obtained from the Oncomine database. (C-D) The correlation between the mRNA expression of HSDL2 and survival time of breast cancer patients was predicted by using KM plotter and the Protein Atlas database. 

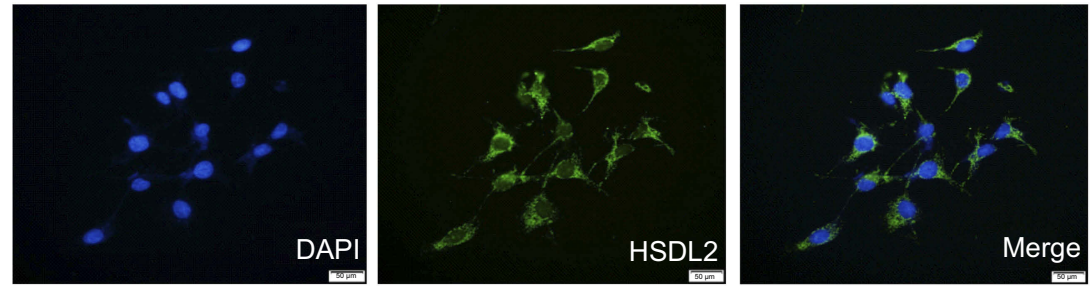

Figure 2 IF staining of HSDL2 in MDA-MB-23I breast cancer cells.

Notes: HSDL2 protein is mainly located in the cytoplasm of MDA-MB-23I cells. (Blue for DAPI, green for HSDL2).

\section{Correlations between HSDL2 and the clinicopathological features of breast cancer}

To assess the association between HSDL2 protein expression and the clinicopathological parameters of breast cancer, statistical analysis was performed based on the IHC staining of HSDL2 in breast cancer samples. The expression of HSDL2 protein was significantly associated with the histological grade and clinical stage of breast cancer. The strongly positive rate of HSDL2 expression in grade 1 breast cancer $(17 / 25,68.0 \%)$ was significantly lower than that in grade $2(85 / 92,92.3 \%)$ and grade $3(2 / 2,100 \%)$ $(p<0.01)$ breast cancer. Similarly, for the clinical stage, the strongly positive rate of HSDL2 protein expression in breast cancer patients with clinical stage II-III was $89.2 \%$ (99/111), which was significantly higher than that in patients with clinical stage 0 -I $(62.5 \%, 5 / 8)(p<0.05)$ (Figure 3E and F; Table 3). However, the positive rate of HSDL2 expression was not associated with age, lymph node metastasis, ER, PR or HER2 expression status.

\section{High expression of HSDL2 is an independent biomarker for poor prognosis of breast cancer patients}

To further substantiate the importance of high HSDL2 expression in breast cancer progression, we analysed the
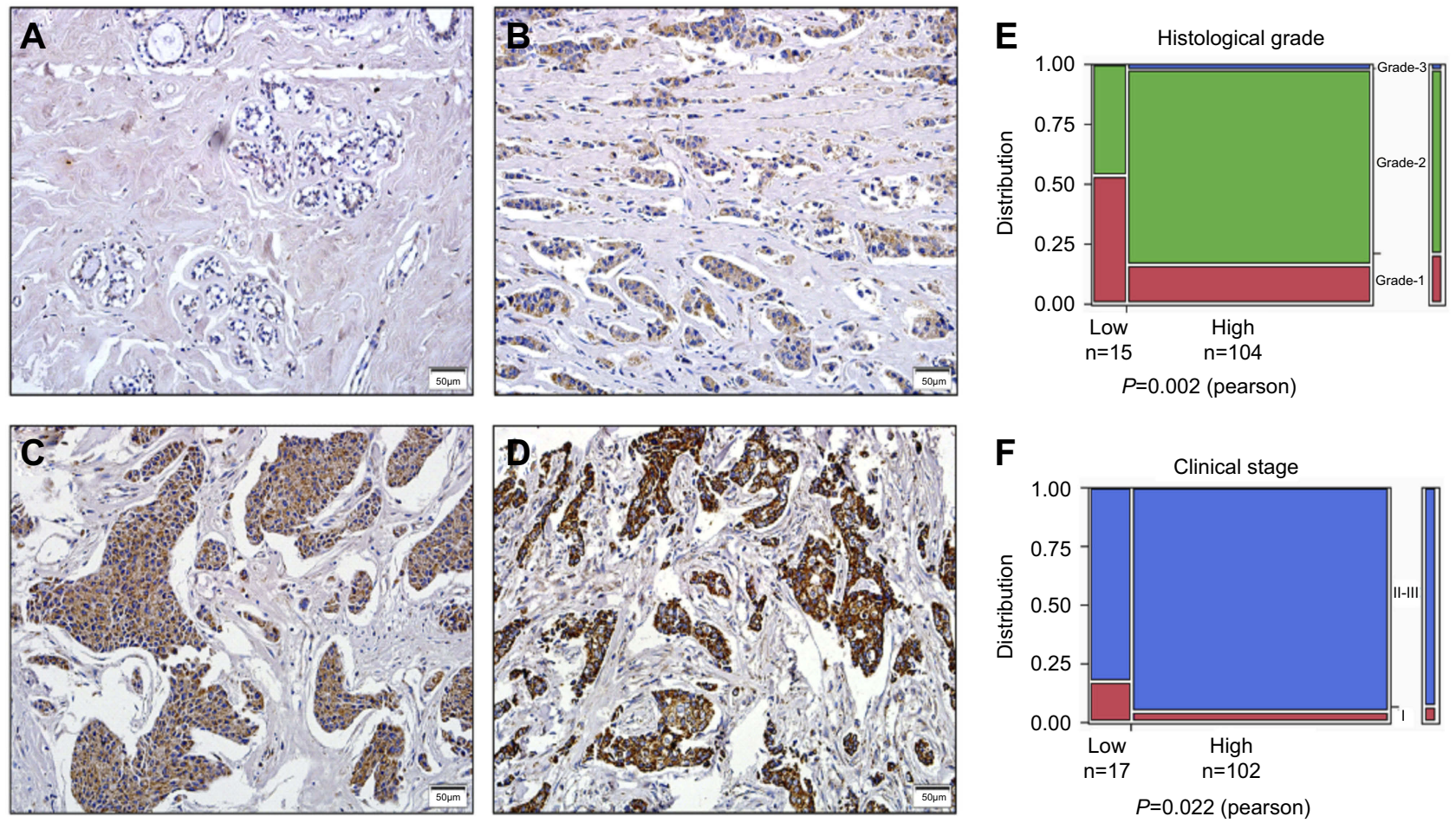

Figure 3 IHC staining of HSDL2 protein in breast cancer and normal breast tissues.

Notes: (A) Negative HSDL2 protein in normal breast epithelial tissues. (B) Weakly positive HSDL2 protein in breast cancer tissues. (C) Moderately positive HSDL2 protein in breast cancer tissues. (D) Strongly positive HSDL2 protein in breast cancer tissues. Original magnification, A-D: $\times 200$. (E-F) The expression level of HSDL2 protein was significantly related to differentiation $(p=0.002)$ and clinical stage $(p=0.022)$. 
Table 2 HSDL2 protein expression in breast cancer

\begin{tabular}{|l|l|l|l|l|l|l|l|}
\hline \multirow{2}{*}{ Diagnosis } & \multirow{2}{*}{ No. of cases } & \multicolumn{3}{|l|}{ HSDL2 expression } & \multirow{2}{*}{ Positive rate (\%) } & \multirow{2}{*}{ Strongly positive rate (\%) } \\
\cline { 3 - 7 } & & - & + & ++ & +++ & & $48.7^{* *}$ \\
\hline Breast cancers & 119 & 15 & 46 & 46 & 12 & $87.4^{* *}$ & 12.5 \\
\hline Normal tissues & 40 & 30 & 5 & 5 & 0 & 25 & \\
\hline
\end{tabular}

Notes: ${ }^{* *} p<0.01$ compared with normal tissues; Positive rate percentage of positive cases with "+", “++", and "+++" staining score; Strongly positive rate percentage of positive cases with "++" and "+++" staining score.

Table 3 Correlation between HSDL2 expression and clinicopathological parameters of breast cancer patients

\begin{tabular}{|c|c|c|c|c|}
\hline $\begin{array}{l}\text { Clinical } \\
\text { features }\end{array}$ & $\begin{array}{l}\text { No. of } \\
\text { Cases }\end{array}$ & $\begin{array}{l}\text { Positive } \\
\text { cases (\%) }\end{array}$ & $\chi^{2}$ & $p$-value \\
\hline $\begin{array}{l}\text { Tumor size } \\
\text { TI } \\
\text { T2-T3 }\end{array}$ & $\begin{array}{l}25 \\
94\end{array}$ & $\begin{array}{l}22(88.0) \\
82(87.2)\end{array}$ & 0.001 & 0.995 \\
\hline $\begin{array}{l}\text { Histological } \\
\text { Grade } \\
\text { Grade-I } \\
\text { Grade-2 } \\
\text { Grade-3 }\end{array}$ & $\begin{array}{l}25 \\
92 \\
2\end{array}$ & $\begin{array}{l}17(68.0) \\
85(92.3) \\
2(100.0)\end{array}$ & 12.380 & $0.002 * *$ \\
\hline $\begin{array}{l}\text { Clinical } \\
\text { Stage } \\
\text { I } \\
\text { II- III }\end{array}$ & $\begin{array}{l}8 \\
111\end{array}$ & $\begin{array}{l}5(62.5) \\
99(89.2)\end{array}$ & 5.236 & $0.022^{*}$ \\
\hline $\begin{array}{l}\text { LN metasta- } \\
\text { sis } \\
\quad \text { Absent } \\
\text { Presence }\end{array}$ & $\begin{array}{l}76 \\
43\end{array}$ & $\begin{array}{l}65(85.5) \\
39(90.6)\end{array}$ & 0.547 & 0.460 \\
\hline $\begin{array}{l}\text { ER } \\
\text { Positive } \\
\text { Negative }\end{array}$ & $\begin{array}{l}76 \\
43\end{array}$ & $\begin{array}{l}67(88.2) \\
37(86.0)\end{array}$ & 0.556 & 0.456 \\
\hline $\begin{array}{l}\text { PR } \\
\text { Positive } \\
\text { Negative }\end{array}$ & $\begin{array}{l}66 \\
53\end{array}$ & $\begin{array}{l}59(89.4) \\
45(84.9)\end{array}$ & 0.039 & 0.843 \\
\hline $\begin{array}{l}\text { HER2 } \\
\text { Positive } \\
\text { Negative }\end{array}$ & $\begin{array}{l}28 \\
91\end{array}$ & $\begin{array}{l}25(89.3) \\
79(86.8)\end{array}$ & 0.006 & 0.939 \\
\hline
\end{tabular}

Note: ${ }^{*} p<0.05$, and ${ }^{*} p<0.01$.

Abbreviations: ER, estrogen receptor; PR, progesterone receptor; HER2, human epidermal growth factor receptor-2; LN, metastasis lymph node metastasis.

correlation between HSDL2 expression and the overall survival (OS) rates of 119 breast cancer patients by using the Kaplan-Meier method. We found that patients with high HSDL2 expression had lower OS rates than those with low HSDL2 expression ( $p=0.043$, log-rank=4.091). Remarkably, for PR (-) breast cancer patients, OS rates were significantly higher in patients with low HSDL2 protein expression than in those with high HSDL2 expression $(p=0.046$, log-rank=3.998) (Figure 4A and B). However, the expression status of HSDL2 protein was not correlated with $\mathrm{OS}$ in $\mathrm{PR}(+)$ breast cancer patients $(p=0.223$, log-rank=1.485) (Figure 4C).

Univariate analysis demonstrated that clinical stage ( $p=0.013)$, ER status $(p=0.008)$, PR status $(p=0.002)$, and HSDL2 expression status $(p=0.047)$ were significantly associated in patients with breast cancer. Further multivariate analysis using the Cox proportional hazards model revealed that HSDL2 overexpression was a significant independent prognostic factor for survival along with clinical stage $(p=0.007)$ and PR status $(p=0.027)$ in breast cancer patients (Table 4). These data suggested that HSDL2 could be a valuable prognostic factor in breast cancer.

\section{Knockdown of HSDL2 inhibits the proliferation of breast cancer cells in vitro} To examine whether HSDL2 could affect breast cancer cell growth, we detected HSDL2 expression in different breast cancer cell lines (Figure 5A). Then, MDA-MB-231 and MDA-MB-468 cells were transfected with si-HSDL2. Western blot analysis showed that si-HSDL2 effectively downregulated the protein expression level of HSDL2 in MDA-MB-231 and MDA-MB-468 cells (Figure 5B and C).

Then, we detected cell viability by using the MTT assay. The results showed that the efficient knockdown of HSDL2 in cells significantly decreased cell viability in vitro, suggesting the important function of HSDL2 in cell viability (Figure 5D). We next assessed the colony formation abilities before and after HSDL2 silencing and found that the knockdown of HSDL2 remarkably reduced cell survival and decreased breast cancer cell proliferation (Figure 5E and F). In addition, SKBR-3 cells were transfected with HSDL2 overexpression plasmid. Then, MTT assay and colony formation assay were performed. The results showed that HSDL2 overexpression promotes cell 
A

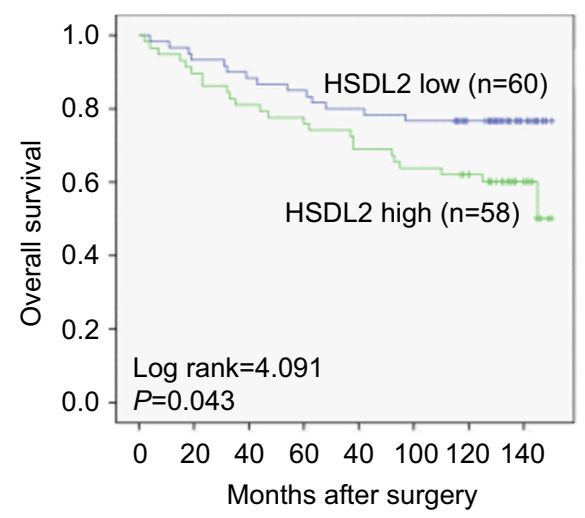

B

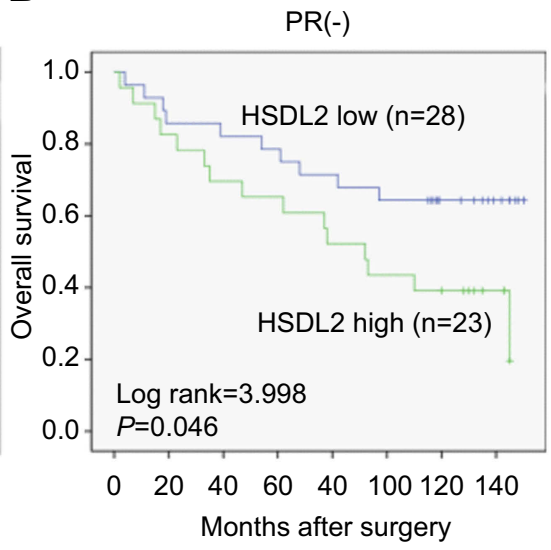

C

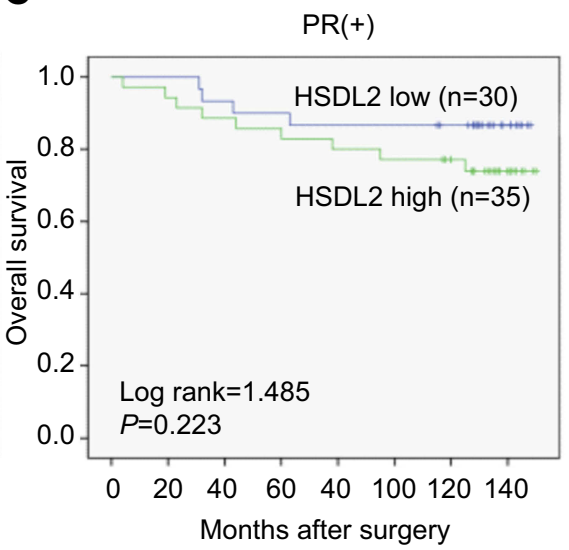

Figure 4 The correlation between HSDL2 expression and the prognosis of breast cancer patients.

Notes: (A) Kaplan-Meier analysis of overall survival rates in 119 breast cancer patients in relation to HSDL2 expression. (B-C) Kaplan-Meier analysis of overall survival rates in 119 breast cancer patients with or without HSDL2 expression in relation to PR status.

Abbreviations: $\mathrm{H}$, high; L, low.

Table 4 Univariate survival analyses (Cox regression model) of various factors in patients with breast cancer

\begin{tabular}{|c|c|c|c|c|c|c|c|}
\hline Factors & B & SE & Wald & HR & \multicolumn{2}{|c|}{$95 \% \mathrm{Cl}$} & $p$-value \\
\hline \multicolumn{8}{|l|}{ Univariate } \\
\hline Age (years) & 0.011 & 0.012 & 0.747 & 1.011 & 0.986 & 1.036 & 0.388 \\
\hline Tumor size & 0.266 & 0.342 & 0.602 & 1.304 & 0.667 & $2.55 I$ & 0.438 \\
\hline Differentiation & 0.333 & 0.480 & 0.481 & 1.395 & 0.544 & 3.575 & 0.488 \\
\hline $\mathrm{LN}$ metastasis & 0.295 & 0.351 & 0.708 & 1.344 & 0.675 & 2.675 & 0.400 \\
\hline Clinical stage & 0.817 & 0.329 & 6.159 & 2.263 & 1.187 & 4.315 & $0.013^{*}$ \\
\hline ER & -0.857 & 0.325 & 6.931 & 0.425 & 0.224 & 0.803 & $0.008 * *$ \\
\hline PR & -1.069 & 0.343 & 9.725 & 0.343 & 0.175 & 0.672 & $0.002 * *$ \\
\hline HER2 & -0.244 & 0.398 & 0.377 & 0.783 & 0.359 & 1.709 & 0.539 \\
\hline HSDL2 & 0.667 & 0.337 & 3.933 & 1.949 & 1.008 & 3.770 & $0.047^{*}$ \\
\hline \multicolumn{8}{|l|}{ Multivariate } \\
\hline Clinical stage & 0.890 & 0.332 & 7.190 & 2.436 & 1.271 & 4.670 & $0.007^{* *}$ \\
\hline ER & -0.272 & 0.437 & 0.387 & 0.762 & 0.323 & 1.795 & 0.534 \\
\hline PR & -1.020 & 0.460 & 4.919 & 0.361 & 0.146 & 0.888 & $0.027^{*}$ \\
\hline HSDL2 & 0.804 & 0.345 & 5.437 & 2.235 & 1.137 & 4.393 & $0.020^{*}$ \\
\hline
\end{tabular}

Note: ${ }^{*} p<0.05$, and $* * p<0.01$.

Abbreviations: ER, estrogen receptor; PR, progesterone receptor; HER2, human epidermal growth factor receptor-2; LN, metastasis lymph node metastasis; B, coefficient; $\mathrm{SE}$, standard error; Wald, wald statistic; $\mathrm{HR}$, hazard ratio; $\mathrm{Cl}$, confidence interval.

proliferation (Figure S1). These data suggest that HSDL2 is an essential regulator of breast cancer growth.

\section{Knockdown of HSDL2 induced cell cycle arrest in breast cancer}

To investigate the mechanism underlying the antiproliferative effect of HSDL2 silencing in breast cancer cells, we determined the cell cycle phase distribution in the efficient knockdown of HSDL2 by using flow cytometry. The results showed that HSDL2 silencing increased the percentage of cells in G0/G1 phase arrest, which was accompanied by a decrease in the G2/M phase and $\mathrm{S}$ phase (Figure 6A and $\mathrm{B}$ ). Then, we performed a Western blot assay to detect the expression of cell cycle regulatory proteins in breast cancer cells. The results showed that cyclin-dependent kinase 1 (CDK1), cyclin B1, and cyclin D1 expression were decreased after HSDL2 silencing. In contrast, cyclin-dependent kinase inhibitors p21, known as a tumor suppressor, 
A
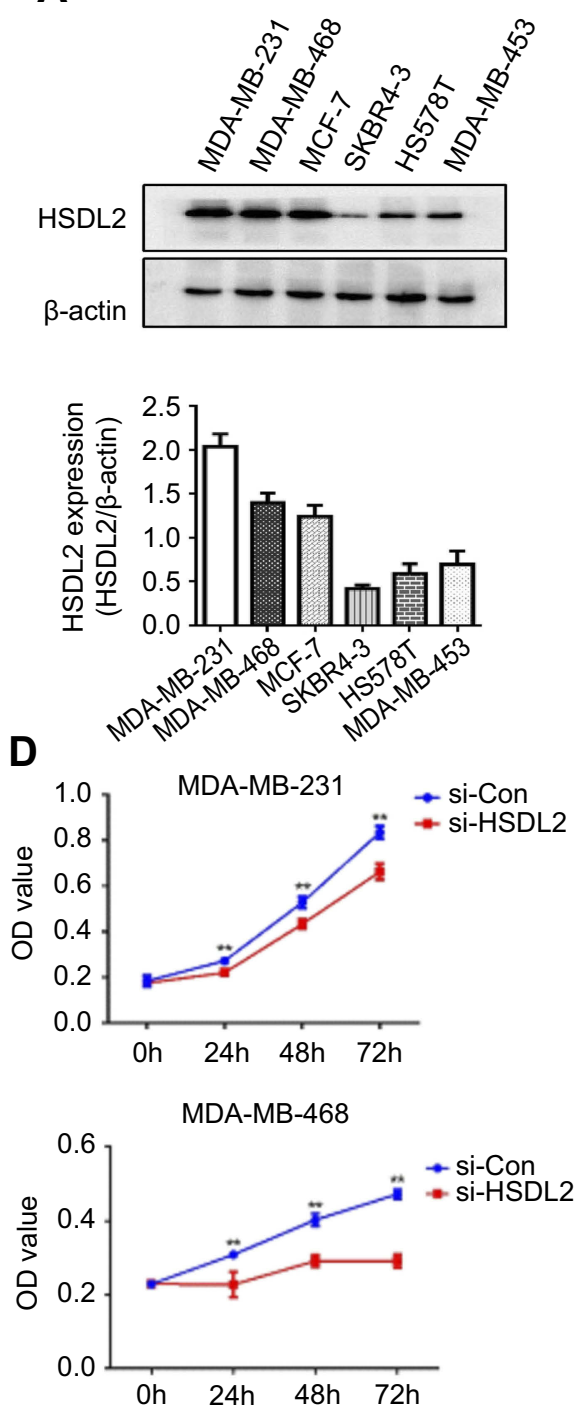

B
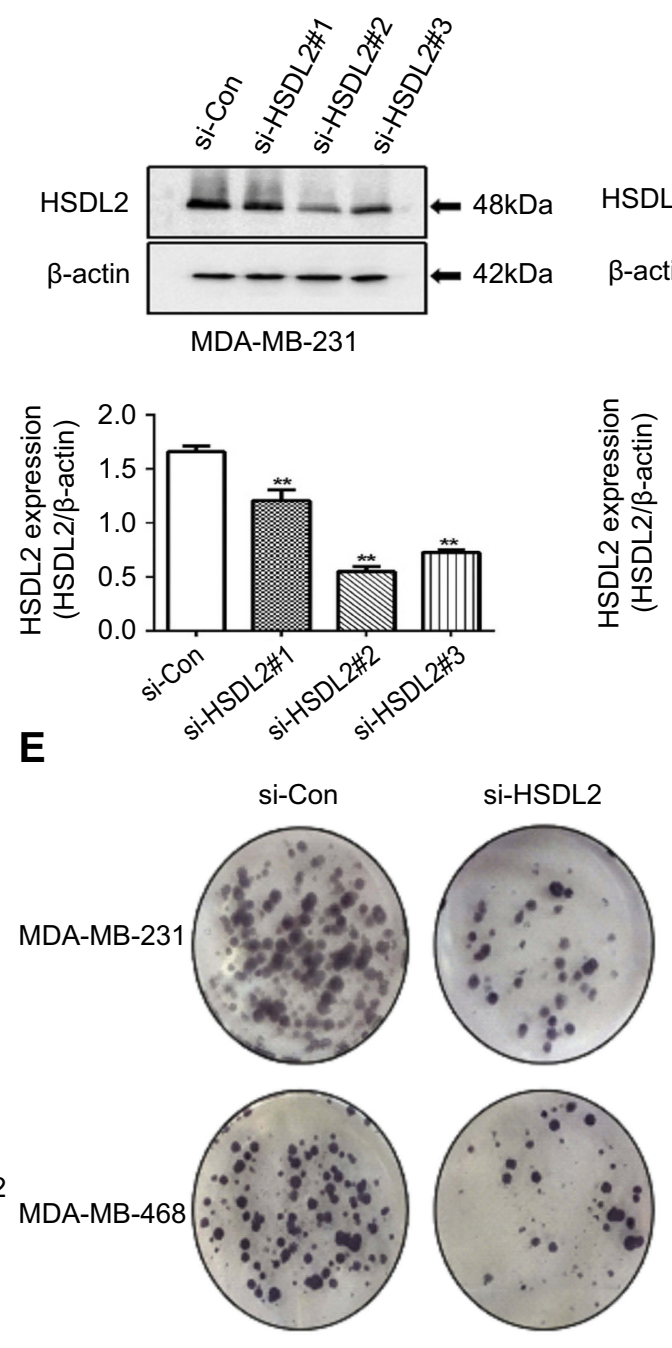

C
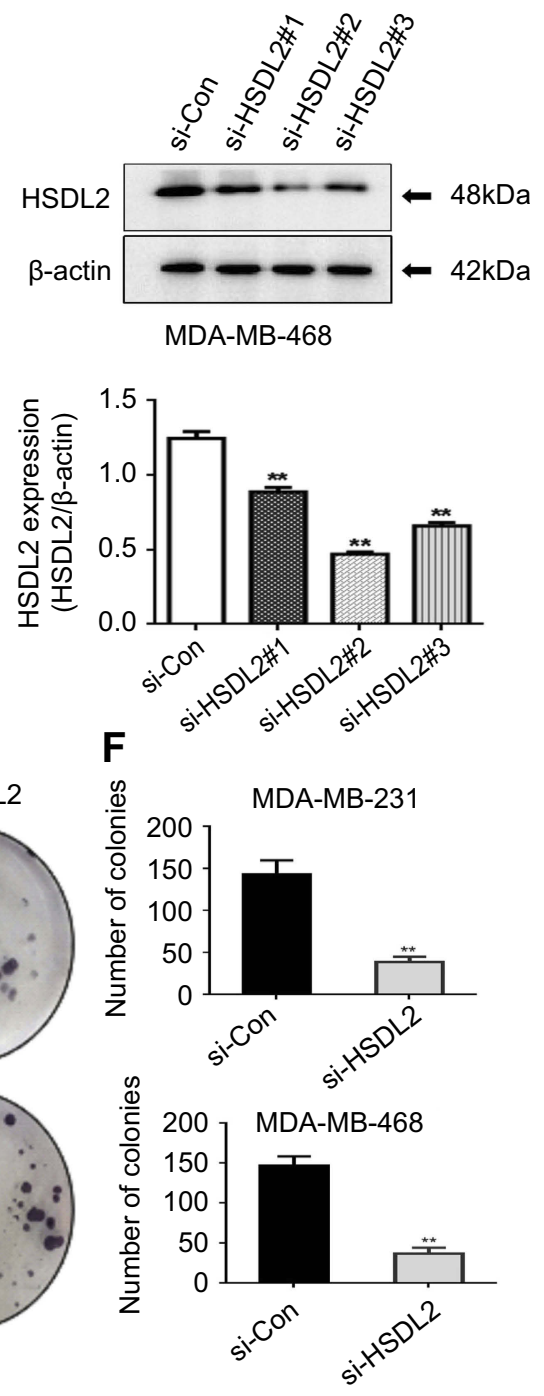

Figure $\mathbf{5}$ Knockdown of HSDL2 suppresses the proliferation of breast cancer cells.

Notes: (A) HSDL2 expression was detected in different breast cancer cell lines. (B-C) HSDL2 protein expression was inhibited in si-HSDL2-transfected MDA-MB-23I and MDA-MB-468 cells compared with si-control cells, as demonstrated by Western blot. (D-F) The proliferation capability of the transfected cells was detected by MTT and colony formation assays. Data are shown as the mean \pm SEM from three independent experiments $\left({ }^{*} p<0.05 ; *^{*} p<0.01\right)$.

was increased in the si-HSDL2 group, while the expression of p53 was not altered (Figure 6C and D). In consideration of off-target effect, another si-RNA against HSDL2 was transfected in MDA-MB-231 cells, and cell proliferation and cell cycle distribution were detected (Figure S2). These results indicated that HSDL2 knockdown suppressed breast cancer cell proliferation through the induction of cell cycle arrest.

\section{Discussion}

The HSDL2 protein contains a D-terminal sterol carrier protein domain, indicating that HSDL2 belongs to the short-chain dehydrogenase (SDR) family. The HSDL2 sequence is found in the 32 regions of the long arm of chromosome 9, and the cDNA length is $3211 \mathrm{bp}$. The protein consists of 418 amino acids and contains a sterol carrier protein-2 (SCP2) domain. ${ }^{12,13}$

Recently, researchers have focused on studying the biological functions of the HSDL2 protein in oncogenesis. Sun et al reported that HSDL2 was deregulated in ovarian cancers, and a high expression of HSDL2 protein was correlated with poor outcomes. ${ }^{10}$ Ruokun et al also reported that HSDL2 was significantly overexpressed in glioma. ${ }^{9}$ Though the association between HSDL2 expression and oncogenesis has been reported, to our knowledge, this is the first report of the 
A

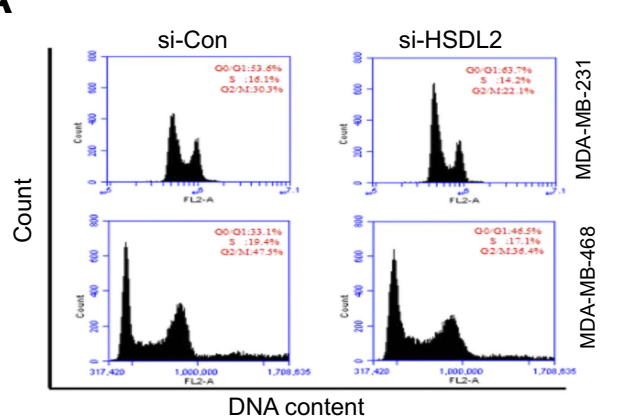

B

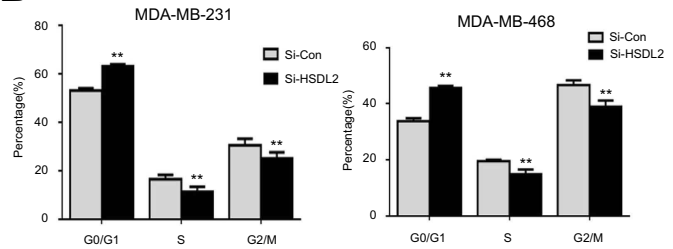

C
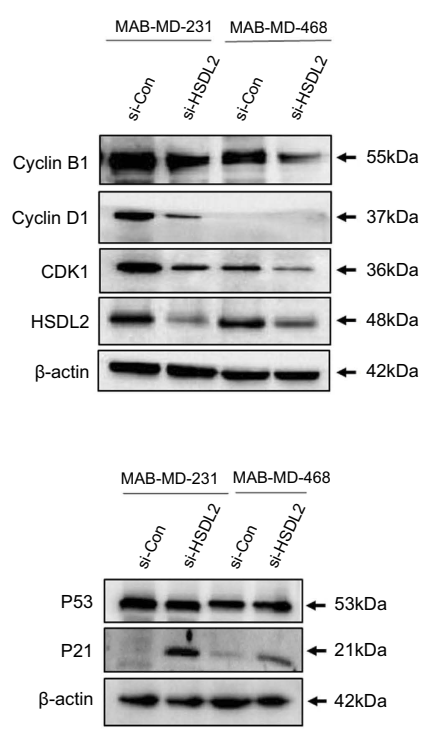

D
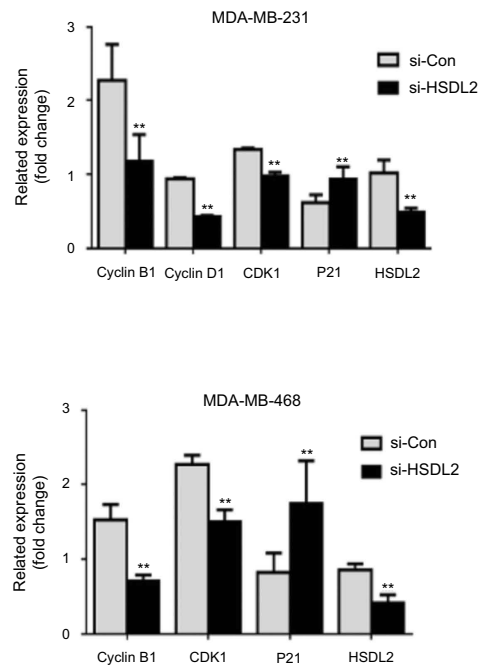

Figure 6 Knockdown of HSDL2 induces cell cycle arrest.

Notes: (A-B) The cell cycle profiles were determined by PI staining, and the percentage of cells in each phase was determined by flow cytometry analysis. (C-D) The expression levels of the cell cycle regulatory proteins in the transfected cells were detected by Western blot. $\beta$-actin was used as a loading control $(* p<0.05$; $* * p<0.0 \mathrm{I})$.

prognostic value of HSDL2 expression in breast cancers. We found that HSDL2 was significantly upregulated in breast cancers and associated with histological grade and clinical stage. The most evident impact of HSDL2 expression was seen for overall survival, both in the full cohort and in the subgroup analysis of patients with PR-negative tumours. These results suggest that HSDL2 could be a prognostic marker for breast cancer patients.

Numerous studies have indicated that the expression levels of the HSDL2 gene are significantly increased after high cholesterol feeding in mice. ${ }^{14}$ Because other subfamilies of steroid dehydrogenase can promote cholesterol metabolism and steroid hormone synthesis, HSDL2 is believed to be involved in the cholesterol metabolism pathway and control cholesterol synthesis. Since cholesterol is the precursor of steroid hormones involved in cancer promotion and inhibition, deregulation of cholesterol metabolism was frequently occurred in cancer development. ${ }^{15}$ Not only that, metabolic productions and enzymes at different points in the cholesterol metabolism has different functions in breast cancer progression. For example, 27-hydroxycholesterol (27HC), one of the cholesterol metabolites, suppresses breast cancer growth through interacting with the estrogen receptor (ER), while $11 \beta$ hydroxysteroid-dehydrogenase-type-2 (11ßHSD2) promotes breast cancer cell growth. ${ }^{16,17}$ Since the opposing properties of cholesterol metabolites and enzymes, it is important to quantitatively profile sterols and oxysterols in tumor cells and also measure the expression of genes and enzymes controlling the metabolism in cancers. ${ }^{15}$

In this study, we found that the knockdown of HSDL2 suppressed breast cancer cell proliferation and induced cell cycle arrest in the G1 phase. Current studies also reported that the knockdown of HSDL2 suppressed cell proliferation and induced cell cycle arrest in both ovarian cancer and glioma. ${ }^{9,10}$ However, an opposite result was also reported by Zhang et al They found that the expression of HSDL2 was downregulated in cholangiocarcinoma and functioned as a tumour suppressor. ${ }^{18}$ These data highlight the important role of HSDL2 in breast and other cancers, and the role of HSDL2 in cancer may be cell- and tissue-specific.

Cholesterol and its metabolites are essential components of plasma membranes and plays a key role in cell mitosis and intracellular signal transduction. ${ }^{19,20}$ Additionally, recent studies also found that the cholesterol metabolites could bind to the nuclear receptor, and lead to breast cancer cell proliferation. ${ }^{17}$ We hypothesized that HSDL2 knockdown caused cell growth reduction and cell cycle arrest partially due to an inhibition of cholesterol metabolism. However, further studies are required to confirm whether HSDL2 could regulate cholesterol metabolism in breast cancers, and the underlying molecular mechanisms also need to be discussed.

\section{Conclusion}

In conclusion, these findings suggest a possible relevance between HSDL2 expression and the prognosis of breast 
cancer patients. HSDL2 may serve as a potential target for breast cancer and provide new options for physicians in clinical therapy.

\section{Acknowledgments}

This research was supported by the National Natural Science Funds of China (no. 31760313), the Youth Scientific Research Fund of Jilin Province (20170520015JH, 20150520048JH), the Funds of Changbai Mountain Scholar Project and Key Laboratory of the Science and Technology Department of Jilin Province.

\section{Author contributions}

All authors contributed toward data analysis, drafting and revising the paper, gave final approval of the version to be published and agree to be accountable for all aspects of the work.

\section{Disclosure}

The authors report no conflicts of interest in this work.

\section{References}

1. Arveux P, Bertaut A. Epidemiology of breast cancer. Rev Prat. 2013;63:1362-1366.

2. Torre LA, Bray F, Siegel RL, Ferlay J, Lortet-Tieulent J, Jemal A. Global cancer statistics, 2012. CA Cancer J Clin. 2015;65:87-108. doi:10.3322/caac. 21262

3. Smith I, Procter M, Gelber Richard D, et al. 2-year follow-up of trastuzumab after adjuvant chemotherapy in HER2-positive breast cancer: a randomised controlled trial. Lancet. 2007;369:29-36. doi:10.1016/S0140-6736(07)60028-2

4. Kowalik D, Haller F, Adamski J, Moeller G. In search for function of two human orphan SDR enzymes: hydroxysteroid dehydrogenase like 2 (HSDL2) and short-chain dehydrogenase/reductase-orphan (SDR-O). Steroid Biochem Mol Biol. 2009;117:117-124. doi:10.1016/j. jsbmb.2009.08.001

5. Oppermann UC, Salim S, Tjernberg LO, Terenius L, Jörnvall H. Binding of amyloid beta-peptide to mitochondrial hydroxyacyl-CoA dehydrogenase (ERAB): regulation of an SDR enzyme activity with implications for apoptosis in Alzheimer's disease. FEBS Lett. 1999;451:238-242.

6. Chang N-S, Schultz L, Hsu L-J, Lewis J, Su M, Sze C-I. 17beta-Estradiol upregulates and activates WOX1/WWOXv1 and WOX2/WWOXv2 in vitro: potential role in cancerous progression of breast and prostate to a premetastatic state in vivo. Oncogene. 2005;24:714-723. doi:10.1038/sj. onc. 1208124
7. Persson B, Kallberg Y, Bray JE, et al. The SDR (short-chain dehydrogenase/reductase and related enzymes) nomenclature initiative. Chem Biol Interact. 2009;178:94-98. doi:10.1016/j. cbi.2008.10.040

8. Dai J, Xie Y, Wu Q, et al. Molecular cloning and characterization of a novel human hydroxysteroid dehydrogenase-like 2 (HSDL2) cDNA from fetal brain. Biochem Genet. 2003;41:165-174.

9. Ruokun C, Yake X, Fengdong Y, Xinting W, Laijun S, Xianzhi L. Lentivirus-mediated silencing of HSDL2 suppresses cell proliferation in human gliomas. Tumour Biol. 2016;37:15065-15077. doi:10.1007/ s13277-016-5402-6

10. Sun Q, Zhang Y, Su J, Li T, Jiang Y. Role of hydroxysteroid dehydrogenase-Like 2 (HSDL2) in human ovarian cancer. Med Sci Monit. 2018;24:3997-4008. doi:10.12659/MSM.909418

11. Rhodes Daniel R, Jianjun Y, Shanker K, et al. ONCOMINE: a cancer microarray database and integrated data-mining platform. Neoplasia. 2004;6:1-6.

12. Kallberg Y, Oppermann U, Jörnvall H, B. P. Short-chain dehydrogenases/reductases (SDRs). Eur J Biochem. 2002;269:4409-4417.

13. Cheng Z, Li Y, Sui C, Sun X, Xie Y. Synthesis, purification and crystallographic studies of the C-terminal sterol carrier protein type 2 (SCP-2) domain of human hydroxysteroid dehydrogenase-like protein 2. Acta Crystallogr F Struct Biol Commun. 2015;71:901-905. doi:10.1107/S2053230X15008559

14. Gallegos AM, Atshaves BP, Storey SM, et al. Gene structure, intracellular localization, and functional roles of sterol carrier protein-2. Prog Lipid Res. 2001;40:498-563.

15. Silvente-Poirot S, Poirot M. Cancer. Cholesterol and cancer, in the balance. Science. 2014;343:1445-1446. doi:10.1126/science. 1252787

16. Nelson ER, Wardell SE, Jasper JS, et al. 27-Hydroxycholesterol links hypercholesterolemia and breast cancer pathophysiology. Science. 2013;342:1094-1098. doi:10.1126/science. 1241908

17. Voisin $M$, de Medina $P$, Mallinger $A$, et al. Identification of a tumor-promoter cholesterol metabolite in human breast cancers acting through the glucocorticoid receptor. Proc Natl Acad Sci U S A. 2017;114:E9346-E9355. doi:10.1073/pnas.1707965114

18. Zhang D-Y, Liu Z, Lu Z, et al. Lentivirus-mediated overexpression of HSDL2 suppresses cell proliferation and induces apoptosis in cholangiocarcinoma. Onco Targets Ther. 2018;11:7133-7142. doi:10.2147/OTT.S176410

19. Yamauchi Y, Reid PC, Sperry JB, et al. Plasma membrane rafts complete cholesterol synthesis by participating in retrograde movement of precursor sterols. J Biol Chem. 2007;282:34994-35004. doi:10.1074/jbc.M703653200

20. Singh P, Saxena R, Srinivas G, Pande G, Chattopadhyay A. Cholesterol biosynthesis and homeostasis in regulation of the cell cycle. PLoS One. 2013;8:e58833. doi:10.1371/journal. pone. 0058833 


\section{Supplementry materials}

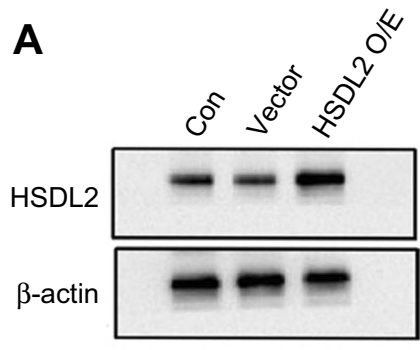

D

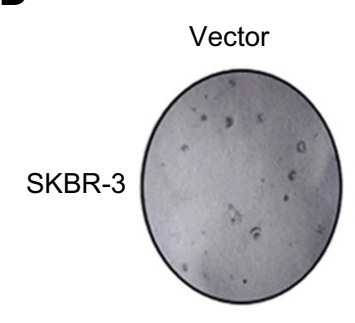

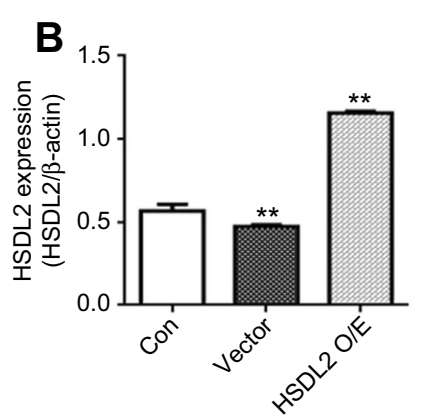

E

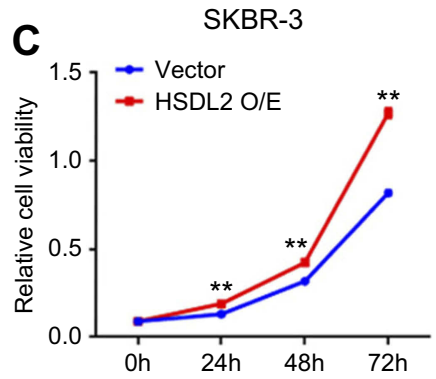

HSDL2 O/E
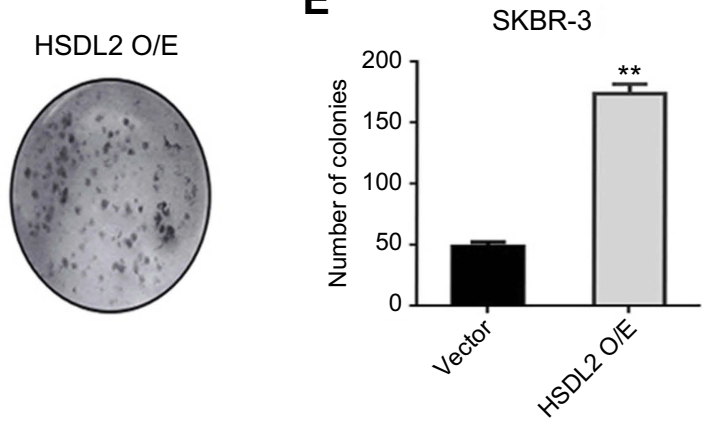

Figure SI Overexpression of HSDL2 promotes the proliferation of breast cancer cells.

Notes: (A-B) SKBR-3 cells were transfected with HSDL2 overexpression plasmid. The transfection efficiency was confirmed by Western blot. (C-E) The proliferation capability of the transfected cells was detected by MTT and colony formation assays. Data are shown as the mean \pm SEM from three independent experiments $\left({ }^{*} p<0.05 ; * * p<0.01\right)$. 
A

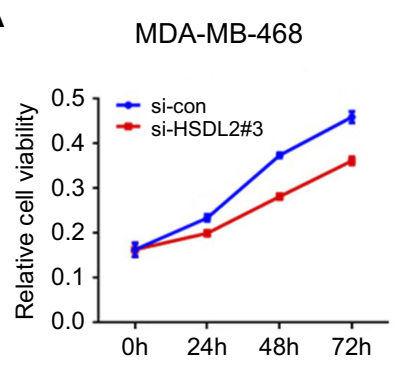

B

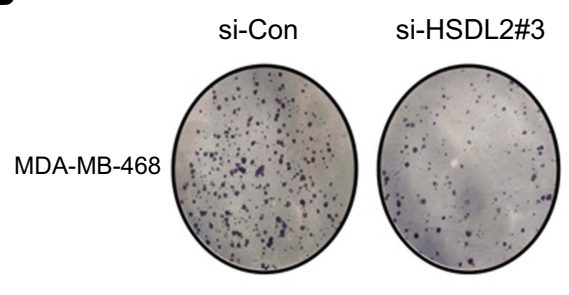

C

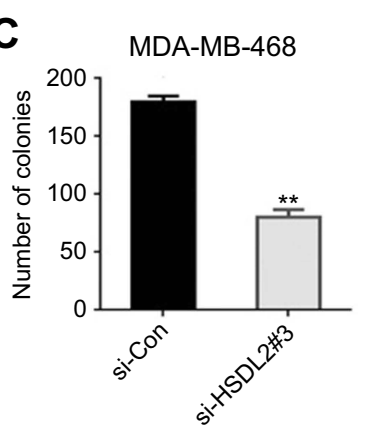

F

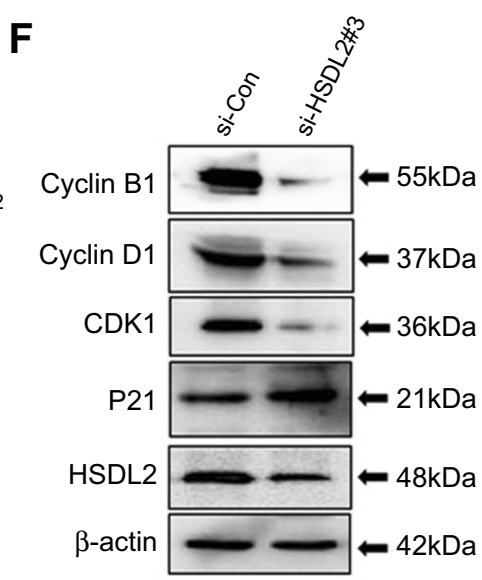

D

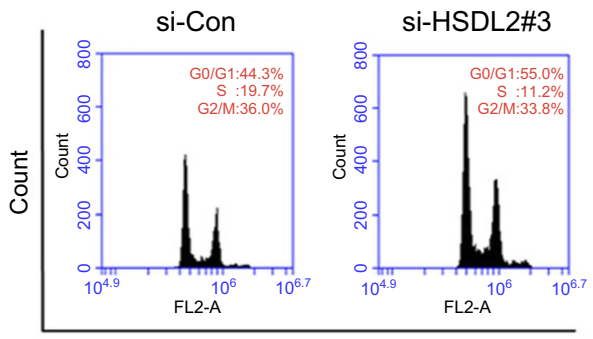

DNA content
E

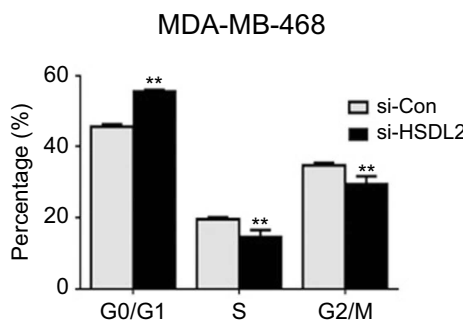

Figure S2 Knockdown of HSDL2 suppresses the proliferation and induces cell cycle arrest.

Notes: (A-C) The proliferation capability of the si-HSDL2 transfected cells was detected by MTT and colony formation assays. Data are shown as the mean \pm SEM from three independent experiments. (D-E) The cell cycle profiles were determined by PI staining, and the percentage of cells in each phase was determined by flow cytometry analysis. (F) The expression levels of the cell cycle regulatory proteins in the transfected cells were detected by Western blot. $\beta$-actin was used as a loading control $\left({ }^{*} p<0.05\right.$; $\left.*^{*} p<0.0 \mathrm{I}\right)$.

\section{Publish your work in this journal}

Cancer Management and Research is an international, peer-reviewed open access journal focusing on cancer research and the optimal use of preventative and integrated treatment interventions to achieve improved outcomes, enhanced survival and quality of life for the cancer patient.
The manuscript management system is completely online and includes a very quick and fair peer-review system, which is all easy to use. Visit http://www.dovepress.com/testimonials.php to read real quotes from published authors. 